\title{
Spontaneous pneumothorax: epidemiology, pathophysiology and cause
}

\author{
M. Noppen
}

ABSTRACT: Spontaneous pneumothorax represents a common clinical problem. An overview of relevant and updated information on epidemiology, pathophysiology and cause(s) of spontaneous (primary and secondary) pneumothorax is described.

\section{KEYWORDS: Epidemiology, pathogenesis, pneumothorax}

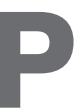

neumothorax is defined as the presence of air in the pleural space. Although intrapleural pressures are negative throughout most of the respiratory cycle [1], air does not enter into the pleural space because the sum of all the partial pressures of gases in the capillary blood averages only $93.9 \mathrm{kPa} \quad(706 \mathrm{mmHg}$ ). Hence, net movement of gases from the capillary blood into the pleural space would require pleural pressures lower than $-54 \mathrm{mmHg}$ (i.e. lower than $-36 \mathrm{cmH}_{2} \mathrm{O}$ ), which hardly ever occur in normal circumstances [2]. Hence, if air is present in the pleural space, one of three events must have occurred: 1) communication between alveolar spaces and pleura; 2) direct or indirect communication between the atmosphere and the pleural space; or 3) presence of gas-producing organisms in the pleural space. From a clinical standpoint, pneumothorax is classified as spontaneous (no obvious precipitating factor present) and nonspontaneous (table 1) [2, 3]. Primary spontaneous pneumothorax (PSP) is defined as the spontaneously occurring presence of air in the pleural space in patients without clinically apparent underlying lung disease.

\section{PRIMARY SPONTANEOUS PNEUMOTHORAX}

PSP has an incidence of 7.4 to 18 cases (ageadjusted incidence) per 100,000 population each year in males, and 1.2 to 6 cases per 100,000 population each year in females $[4,5]$. PSP typically occurs in tall, thin subjects. Other risk factors are male sex and cigarette smoking. Contrary to popular belief, PSP typically occurs at rest; avoiding exercise, therefore, should not be recommended to prevent recurrences [6]. Precipitating factors may be atmospheric pressure changes (which may account for the often observed clustering of PSP)
[7] and exposure to loud music [8]. Almost all patients with PSP report a sudden ipsilateral chest pain, which usually spontaneously resolves within $24 \mathrm{~h}$ [2]. Dyspnoea may be present but is usually mild. Physical examination can be normal in small pneumothoraces. In larger pneumothoraces, breath sounds and tactile fremitus are typically decreased or absent, and percussion is hyper-resonant. Rapidly evolving hypotension, tachypnea, tachycardia and cyanosis should raise the suspicion of tension pneumothorax, which is, however, extremely rare in PSP.

Diagnosis can be confirmed in the majority of cases on an upright posteroanterior (PA) chest radiograph, which also allows an estimation of the pneumothorax size with good accuracy [9]. In cases with a small PSP, computed tomography (CT) may be necessary to diagnose the presence of pleural air. Routine expiratory chest radiographs are useless [10]. It is important to realise that a contralateral shift of the trachea and mediastinum is a completely normal phenomenon in spontaneous pneumothorax, and not at all suggestive for tension pneumothorax; this observation should therefore in no way influence treatment strategies [1].

\section{PATHOGENESIS}

The exact pathogenesis of the spontaneous occurrence of a communication between the alveolar spaces and the pleura remains unknown. Most authors believe that spontaneous rupture of a subpleural bleb, or of a bulla, is always the cause of PSP [11], but alternative explanations are available $[12,13]$. Although the majority of PSP patients, including children [14], present blebs or bullae [15-18], it is unclear how often these lesions actually are the site of air leakage [19-21]. Only a minority of blebs are actually ruptured at the time
CORRESPONDENCE

M. Noppen

Interventional Endoscopy Clinic

Respiratory Division

University Hospital UZ Brussel

101 Laarbeeklaan

B 1090 Brussels

Belgium

E-mail: marc.noppen@uzbrussel.be

Received:

May 252010

Accepted:

May 262010

\section{PROVENANCE}

Publication of this peer-reviewed article was supported by GlaxoSmithKline, Belgium (principal sponsor, European Respiratory Review issue 117). 


\begin{tabular}{l} 
TABLE 1 Clinical classification of pneumothorax \\
Spontaneous \\
Primary: no apparent underlying lung disease \\
Secondary: clinically apparent underlying disease (e.g. chronic \\
obstructive pulmonary disease and cystic fibrosis) \\
Catamenial: in conjunction with menstruation \\
(Neonatal) \\
Traumatic \\
latrogenic: secondary to transthoracic and transbronchial biopsy, \\
central venous catheterisation, pleural biopsy and thoracentesis \\
Non-iatrogenic: secondary to blunt or penetrating chest injury \\
\hline
\end{tabular}

of thoracoscopy or surgery, whereas often other lesions are present ("pleural porosity" [19-21]: areas of disrupted mesothelial cells at the visceral pleura, replaced by an inflammatory elastofibrotic layer with increased porosity, allowing air leakage into the pleural space). The latter phenomenon may explain the high recurrence rates of up to $20 \%$ of bullectomy alone (without associated pleurodesis) as therapy [22-25]. The development of blebs, bullae and areas of pleural porosity may be linked to a variety of factors, including distal airway inflammation [21-26], hereditary predisposition [27], anatomical abnormalities of the bronchial tree [28], ectomorphic physiognomy with more negative intrapleural pressures [29] and apical ischaemia [30] at the apices [31], low body mass index and caloric restriction $[15,32]$, and abnormal connective tissue [33, 34]. The role of increased plasma aluminium concentrations in the pathogenesis of PSP remains unresolved [35, 36].

These lesions may, therefore, predispose to PSP when combined with (largely unknown) precipitating factors; blebs and bullae indeed also occur in up to $15 \%$ of normal subjects [15-17]. New techniques such as fluorescein-enhanced autofluorescence thoracoscopy [37] or infrared thoracoscopy [38] may shed more light on this issue, and may be helpful in the detection of the culprit areas during thoracoscopy or surgery. It should be clear, however, that every therapeutic intervention with the purpose to prevent recurrences of PSP should include a pleurodesis technique, with or without an intervention at the level of the lung parenchyma [39].

\section{SECONDARY SPONTANEOUS PNEUMOTHORAX}

A multitude of respiratory disorders have been described as a cause of spontaneous pneumothorax. The most frequent underlying disorders are chronic obstructive pulmonary disease with emphysema, cystic fibrosis, tuberculosis, lung cancer and HIVassociated Pneumocystis carinii pneumonia, followed by more rare but "typical" disorders, such as lymphangioleiomyomatosis and histiocytosis $X$ (table 2). Because lung function in these patients is already compromised, secondary spontaneous pneumothorax (SSP) often presents as a potentially life-threatening disease, requiring immediate action, in contrast with $\mathrm{PSP}$, which is more of a nuisance than a dangerous condition. The general incidence is almost similar to that of PSP. Depending upon the underlying disease, the peak incidence of SSP can occur later in life, e.g. 60$65 \mathrm{yrs}$ of age in the emphysema population [2].

In SSP, dyspnoea is the most prominent clinical feature; chest pain, cyanosis, hypoxaemia and hypercapnia, sometimes

TABLE $2 \quad \begin{aligned} & \text { Frequent and/or typical causes of secondary } \\ & \text { spontaneous pneumothorax }\end{aligned}$
Airway disease
Emphysema
Cystic fibrosis
Severe asthma
Infectious lung disease
Pneumocystis carinii pneumonia
Tuberculosis
Necrotising pneumonia
Interstitial lung disease
Idiopathic pulmonary fibrosis
Sarcoidosis
Histiocytosis $X$
Lymphangioleiomyomatosis
Connective tissue disease
Rheumatoid arthritis, scleroderma and ankylosing spondylitis
Marfan's syndrome
Ehlers Danlos syndrome
Malignant disease
Lung cancer
Sarcoma

resulting in acute respiratory failure, can also be present. Diagnosis is confirmed on a PA chest radiograph; in bullous emphysema, the differential diagnosis with a giant bulla can be difficult, necessitating CT confirmation [40]. As in PSP, air may enter the pleural space through various mechanisms: direct alveolar rupture (as in emphysema or necrotic pneumonia), via the lung interstitium, or backwards via the bronchovascular bundle and mediastinal pleura (pneumomediastinum). Recurrence rates usually are higher when compared to those for PSP, ranging up to $80 \%$ of cases, as is observed in cystic fibrosis [41].

\section{STATEMENT OF INTEREST}

None declared.

\section{REFERENCES}

1 Jantz MA, Anthony VB. Pathophysiology of the pleura. Respiration 2008; 75: 121-133.

2 Noppen M, Schramel F. Pneumothorax. Eur Respir Mon 2002; 22: 279-296.

3 Baumann MH, Noppen M. Pneumothorax. Respirology 2004; 9: 157-164.

4 Bense L, Eklund G, Wilman LG. Smoking and the increased risk of contracting spontaneous pneumothorax. Chest 1987; 92: 1009-1012.

5 Melton LJ, Hepper NGG, Offord KP. Incidence of spontaneous pneumothorax in Olmsted County, Minnesota: 1050-74. Am Rev Respir Dis 1979; 120: 1379-1382.

6 Bense L, Wilman LG, Hedenstierna G. Onset of symptoms in spontaneous pneumothorax: correlations to physical activity. Eur J Respir Dis 1987; 71: 181-186.

7 Alifano M, Forti Parri SN, Bonfanti B, et al. Atmospheric pressure influences the risk of pneumothorax: beware of the storm! Chest 2007; 131: 1877-1882.

8 Noppen M, Verbanck S, Harvey J, et al. Music: a new cause of primary spontaneous pneumothorax. Thorax 2004; 59: 722-724. 
9 Noppen M, Alexander P, Driesen P, et al. Quantification of the size of primary spontaneous pneumothorax: accuracy of the Light index. Respiration 2001; 68: 396-399.

10 Bradley M, Willams C, Walshaw MJ. The value of routine expiratory films in the diagnosis of pneumothorax. Arch Emerg Med 1991; 8: 115-116.

11 Light RW. Management of spontaneous pneumothorax. Am Rev Respir Dis 1993; 148: 245-248.

12 Sahn SA, Heffner JE. Spontaneous pneumothorax. N Engl J Med 2000; 342: 868-874.

13 Noppen M. Con: blebs are not the cause of primary spontaneous pneumothorax. J Bronchol 2002; 9: 319-325.

14 Guimaraes CV, Donnely LF, Warner BW. CT findings for blebs and bullae in children with spontaneous pneumothorax and comparison with findings in normal age-matched controls. Pediatr Radiol 2007; 37: 879-884

15 Amjadi K, Alvarez GG, Vanderhelst E, et al. The prevalence of blebs and bullae among young healthy adults: a thoracoscopic evaluation. Chest 2007; 132: 1140-1145.

16 Bense L, Lewander R, Eklund G, et al. Non-smoking, non-alpha 1 antitrypsin deficiency-induced emphysema in nonsmokers with healed spontaneous pneumothorax, identified by computed tomography of the lungs. Chest 1993; 103: 433-438.

17 Lesur O, Delorme N, Fromaget JM, et al. Computed tomography in the etiologic assessment of idiopathic spontaneous pneumothorax. Chest 1990; 98: 341-347.

18 Schramel F, Postmus PE, Vanderschueren RG. Current aspects of spontaneous pneumothorax. Eur Respir J 1997; 10: 1372-1379.

19 Randomsky JBH, Hartel W. Pleuraporositat beim idiopatischen spontanpneumothorax [Pleural porosity in idiopathic spontaneous pneumothorax]. Pneumologie 1989; 43: 250-253.

20 Masshof W, Hofer W. Zur pathologie der sogenannten idiopatischen spontanpneumothorax [Pathology of so-called idiopathic spontaneous pneumothorax]. Dtsch Med Wochenschr 1973; 98: 801-805.

21 Ohata M, Suzuki H. Pathogenesis of spontaneous pneumothorax. With special reference to the ultratsructure of emphysematous bullae. Chest 1980; 77: 771-776.

22 Hatz RA, Kaps MF, Meimerakis G, et al. Long-term results after video-assisted thoracoscopic surgery for first-time and recurrent spontaneous pneumothorax. Ann Thorac Surg 2000; 70: 253-257.

23 Korner H, Andersen KS, Stangeland L, et al. Surgical treatment of spontaneous pneumothorax by wedge resection without pleurodesis or pleurectomy. Eur J Cardiothorac Surg 1996; 10: 656-659.

24 Loubani M, Lynch V. Video-assisted thoracoscopic bullectomy and acromycin pleurodesis: an effective treatment for spontaneous pneumothorax. Respir Med 2000; 94: 888-890.

25 Horio H, Nomori H, Kobayashi R, et al. Impact of additional pleurodesis in video-assisted thoracoscopic bullectomy for primary spontaneous pneumothorax. Surg Endosc 2002; 16: 630-634.
26 Schramel F, Meyer CJ, Postmus PE. Inflammation as a cause of spontaneous pneumothorax and emphysema-like changes: results of bronchoalveolar lavage. Eur Respir J 1995; 8: Suppl. 19, 397s.

27 Morrison PJ, Lowry RC, Nevin NC. Familial primary spontaneous pneumothorax consistent with true autosomal dominant inheritance. Thorax 1998; 53: 151-152.

28 Bense L, Eklund G, Wiman LG. Bilateral bronchial anomaly. A pathogenetic factor in spontaneous pneumothorax. Am Rev Respir Dis 1992; 146: 513-516.

29 Fujino S, Inoue S, Tezuka N, et al. Physical development of surgically treated patients with primary spontaneous pneumothorax. Chest 1999; 116: 899-902.

30 Withers JN, Fishback ME, Kiehl PV, et al. Spontaneous pneumothorax. Suggested etiology and comparison of treatment methods. Am J Surg 1964; 108: 772-776.

31 Kawajami Y, Irie T, Kawashima K. Stature, lung height, and spontaneous pneumothorax. Respiration 1982; 43: 35-40.

32 Coxson HO, Chan IHT, Mayo JR, et al. Early emphysema in patients with anorexia nervosa. Am J Respir Crit Care Med 2004 170: 748-752.

33 Neptune ER, Frischmeyer PA, Arking DE, et al. Dysregulation of TGF-beta activation contributes to pathogenesis in Marfan syndrome. Nat Genet 2003; 33: 407-411.

34 Loeys BL, Matthys DM, De Paepe AM. Genetic fibrillinopathies: new insights in molecular diagnosis and clinical management Acta Clin Belg 2003; 58: 3-11.

35 Han S, Sakinci U, Kose SK, et al. The relationship between aluminium and spontaneous pneumothorax: treatment, prognosis, follow up. Interact Cardiovasc Thorac Surg 2004; 3: 79-82.

36 Leo F, Venissac N, Drici MD, et al. Aluminium and spontaneous pneumothorax. A suggestive but unconfirmed hypothesis. Interact Cardiovasc Thorac Surg 2005; 4: 21-22.

37 Noppen M, Dekeukeleire T, Hanon S, et al. Fluorescein enhanced autofluorescence thoracoscopy in primary spontaneous pneumothoarx and normal subjects. Am J Respir Crit Care Med 2006; 174: $26-30$

38 Gotoh M, Yamamoto $\mathrm{Y}$, Igai $\mathrm{H}$, et al. Clinical application of infrared thoracoscopy to detect bullous or emphysematous lesions of the lung. J Thorac Cardiovasc Surg 2007; 134: 1498-1501.

39 Noppen M, Baumann MH. Pathogenesis and treatment of primary spontaneous pneumothorax: an overview. Respiration 2003; 70: 431-438.

40 Bourgouin $\mathrm{P}$, Cousineau G, Lemire $\mathrm{P}$, et al. Computed tomography used to exclude pneumothorax in bullous lung disease. J Can Assoc Radiol 1985; 36: 341-342.

41 Edenborough FB, Hussain I, Stableforth DE. Use of a Heimlich flutter valve for pneumothorax in cystic fibrosis. Thorax 1994; 49 1178-1179. 